\title{
A Numerical Approach to Investigate the Impact of Acid Asphaltene Sludge Formation on Wormholing During Carbonate Acidizing \\ DOI:
}

$10.1115 / 1.4051738$

\section{Document Version}

Accepted author manuscript

Link to publication record in Manchester Research Explorer

Citation for published version (APA):

Khurshid, I., Al-Shalabi, E. W., Afgan, I., \& Al-Attar, H. (2022). A Numerical Approach to Investigate the Impact of Acid Asphaltene Sludge Formation on Wormholing During Carbonate Acidizing. Journal of Energy Resources Technology, 144(6), [063001-1]. https://doi.org/10.1115/1.4051738

Published in:

Journal of Energy Resources Technology

\section{Citing this paper}

Please note that where the full-text provided on Manchester Research Explorer is the Author Accepted Manuscript or Proof version this may differ from the final Published version. If citing, it is advised that you check and use the publisher's definitive version.

\section{General rights}

Copyright and moral rights for the publications made accessible in the Research Explorer are retained by the authors and/or other copyright owners and it is a condition of accessing publications that users recognise and abide by the legal requirements associated with these rights.

\section{Takedown policy}

If you believe that this document breaches copyright please refer to the University of Manchester's Takedown Procedures [http://man.ac.uk/04Y6Bo] or contact uml.scholarlycommunications@manchester.ac.uk providing relevant details, so we can investigate your claim.

\section{OPEN ACCESS}


DOI: 10.1115/1.4051738

\title{
A Numerical Approach to Investigate the Impact of Acid-Asphaltene Sludge Formation on Wormholing During Carbonate Acidizing
}

\author{
Ilyas Khurshid ${ }^{1}$ \\ Khalifa University, Abu Dhabi, P.O. Box 12277, United Arab Emirates \\ ilyas.khushid@ku.ac.ae \\ Emad W. Al-Shalabi \\ Khalifa University, Abu Dhabi, P.O. Box 12277, United Arab Emirates \\ emad.walshalabi@ku.ac.ae \\ Imran Afgan \\ Khalifa University, Abu Dhabi, P.O. Box 12277, United Arab Emirates \\ University of Manchester, Manchester, M13 9PL, United Kingdom \\ imran.afgan@ku.ac.ae
}

\author{
Hazim Al-Attar \\ UAE University, Al Ain, UAE \\ hazim.alattar@uaeu.ac.ae
}

\begin{abstract}
Carbonate acidization is the process of creating wormholes by injecting acid to increase reservoir permeability and oil production. Nevertheless, some reservoir oils are problematic with low asphaltene stability, which affects the wormholing process. The interactions between acid, rock, and asphaltene lead to acid-asphaltene sludge formation, which reduces oil productivity and acid injectivity. Neglecting this sludge formation, leads to over predicting the depth of the wormhole penetration. Therefore, a numerical model was developed in this study to provide a better understanding of acid-asphaltene sludge formation effect on wormhole creation and propagation in carbonates. A $1 D$ radial model was developed by coupling fluid flow equations in porous media with asphaltene deposition and acid-asphaltene reactions. Then, the developed model was validated and utilized to investigate the effects of different parameters on wormholing including asphaltene presence, acid injection volume and concentration, formation temperature and porosity, and asphaltene concentration. Results showed that acid injection in carbonates with asphaltenicoils reduces wormhole penetration from $40 \%$ to total pore blockage as opposed to reservoirs without asphaltene deposition. The findings also highlighted that shallow wormhole penetration is more pronounced with high volume of acid injection, high porous formations, less diluted acid, and high concentration of asphaltene. In addition, there is an optimum acid injection volume at which wormhole penetration is high and its infiltration is deep into the formation. This is the first work to discuss modeling of acid-asphaltene sludge formation and subsequent wormhole development in carbonates, which is particularly important for problematic crude oils.

\section{Keywords}

Wormholing; Asphaltene Deposition; Acid Injection; Acid-Asphaltene Sludge; Irreversible Formation Damage
\end{abstract}

\footnotetext{
${ }^{1}$ Ilyas Khurshid.
} 
Journal of Energy Resources Technology JUNE 2022, Vol. 144 / 063001-1

\section{INTRODUCTION}

47 Chemical reactions in porous media between rock and different injected fluids is of interest in many 48 subsurface geochemical processes including $\mathrm{CO}_{2}$ sequestration, low salinity water injection, polymer

49 injection, surfactant injection, microbial injection, and production enhancement by hydraulic fracturing and

50 acidizing [1-6]. Both experimental and numerical studies play an important role in evaluating the

51 environmental effects and economic viability of these techniques $[7,8]$. The implementation of these

52 techniques, especially the acid injection in carbonates, is complex and challenging. During acid injection in

53 carbonate rocks and particularly limestones, the surface reaction rates are high and thus, the transfer of

54 mass restricts the net reaction rate, originating highly non-uniform and branched dissolution pathways

55 known as wormholes $[9,10]$.

56 A lot of work has been done over the years on the thermal hydraulics and computational efforts

57 in general, [11-31]. However, advanced techniques for reactive transport modelling have only recently

58 started to receive the requisite attention. For example, in [32-35] experimental data was used for model

59 development, validation and penetration of wormholes. The knowledge of these wormholes and their

60 penetration aids have been utilized in determining the effect of acidization on skin factor in the context of

61 improved oil recovery. The development of wormholes could be a consequence of carbon dioxide $\left(\mathrm{CO}_{2}\right)$

62 based enhanced oil recovery (EOR). In $\mathrm{CO}_{2}$ based EOR operations, millions of cubic feet of anthropogenic

$63 \mathrm{CO}_{2}$ is injected in the reservoirs as opposed to only hundreds of cubic feet of acid is injected in an acid job

64 for stimulation [34]. Moreover, in $\mathrm{CO}_{2}$ based EOR operations, the injected $\mathrm{CO}_{2}$ might create a weak acid

65 (carbonic acid) while in acid stimulation, very strong acids such as hydrochloric and hydrofluoric acids are

66 injected. The latter renders the estimation of wormhole in acid stimulation operations more critical

67 compared to $\mathrm{CO}_{2}$ based EOR. Therefore, it is crucial to understand and determine the safety, success, and

68 economic feasibility of oil recovery in highly reactive operations such as acidization.

69 In carbonate reservoirs, acidization is usually conducted by injecting concentrated acid into the

70 formation to enhance permeability and consequently, oil production. In these reservoirs, acid injection at

71 low rates creates shallow and thick wormholes, while injection at high rates creates branched wormholes 
Journal of Energy Resources Technology JUNE 2022, Vol. 144 / 063001-1

72 with shallow penetration. Nevertheless, at optimum injection rate, deep and extended wormholes might

73 be created with least amount of acid [36]. Consequently, several researchers proposed global acidization

74 models [10, 37-40]. These models could determine the amount of acid needed for creating wormhole and

75 could predict the wormhole propagation rate around the wellbore. However, these models ignored the

76 effect of asphaltene presence on wormholing in the porous media. Although in practical acidizing

77 treatments, a solvent preflush is used to dissolve asphaltenes, this paper addresses the cases when preflush

78 could not dissolve all of the asphaltenes leading to an irreversible formation damage.

79 In acid injection operations, acid-oil interaction is an aspect that has received limited attention in

80 wormhole creation and propagation. During an acid job, when the acid interacts with the asphaltenic

81 crudes, the acid might cause instability of dissolved asphaltene leading to asphaltene deposition [41, 42].

82 Consequently, the reaction of the injected acid with asphaltene might form a black and sticky substance in

83 the reservoir, which is known as acid-asphaltene sludge. This material enhances gravity segregation due to

84 its density and forms a layer of acid-asphaltene sludge in the reservoir. Thus, decreasing reservoir

85 permeability and at worse conditions it might completely shut off production. Moreover, in most of the

86 laboratory studies, the wormholing experiments are usually performed in single phase, water-saturated

87 conditions, which do not allow capturing sludge formation [43-45].

88 Houchin et al. [46] performed a number of tests and reported that acid induced asphaltene sludge

89 is formed for crude oils with API gravities $\geq 27^{\circ} \mathrm{API}$ and asphaltene concentration $\leq 3$ wt. \%, and this sludge

90 is more severe for reservoirs under secondary and tertiary recovery activities. Kumar et al. [47] studied the

91 effect of phase saturation on wormholing and showed that it has a significant impact on the acid operation

92 [26]. They experimentally determined an optimum acid injection rate $10 \mathrm{~cm}^{3} / \mathrm{min}$ with minimum branching

93 in the fully water saturated cores. Whereas for the fully oil saturated cores, the optimum acid injection rate

94 was reported at $5 \mathrm{~cm}^{3} / \mathrm{min}$. They also found no optimum rate for waterflooded residual oil cores. However,

95 they ignored the acid-asphaltene reactions, acid-asphaltene sludge formation, and its effects on

96 wormholing process. Similarly, AlMubarak et al. [48] investigated the acid-induced emulsion and the

97 precipitation of asphaltene in low permeability reservoir and they found that acid systems are not

98 compatible with several oils when they interact with each other. 
Journal of Energy Resources Technology JUNE 2022, Vol. 144 / 063001-1

Furui et al. [38] observed a mismatch in predicting wormhole formation during matrix acidizing

100 between theoretically and conventionally developed models as opposed to field data [41]. This observation

101 was based on performing inverse analysis on wormholing data from horizontal and inclined wells in oil and

102 gas fields from Middle East and North Sea. The discrepancy is due to investigating acid-rock reaction and

103 acid-asphaltene reactions separately. Several researchers considered acid-rock reactions while ignored

104 acid-asphaltene reactions [1, 37, 38]. However, Rietjens and Van Haasterecht considered acid-asphaltene

105 reactions and ignored acid-rock reactions [49]. Moreover, Alrashidi et al. [50] analyzed the effect of bio-oil

106 dispersants on asphaltene sludge during acidization and they found that the dispersant could decrease the

107 formation of asphaltene sludge formation. Thus, both aspects of acid-rock and acid-asphaltene reactions

108 need to be studied and further investigated. Nevertheless, in order to understand asphaltene effect during

109 acidization and acid-asphaltene sludge formation, several factors need to be investigated which affect

110 asphaltene deposition, acid-asphaltene reaction, and acid-asphaltene sludge formation.

111 Therefore, in this study, the experimental data of the above sources [43-48] in the literature were

112 used to propose a model, which considers simultaneous acid-rock and acid-asphaltene reactions as well as

113 acid-asphaltene sludge formation. Furthermore, the effect of several factors on wormholing was

114 investigated in both presence and absence of asphaltene slug formation. These factors include presence of

115 asphaltene, acid injection volume, formation temperature, formation porosity, acid concentration, and

116 asphaltene concentration. To the best of our knowledge, there are no published works focusing on

117 modeling acid-asphaltene sludge formation and its subsequent wormhole development. This paper aims at

118 providing a better understanding of the effects of asphaltene deposition and acid-asphaltene sludge

119 formation on wormhole creation and propagation in carbonates.

\section{NUMERICAL MODEL DEVELOPMENT}

122 In this study, reactive transport modeling of sludge formation during acidization was performed by

123 considering the Darcy scale model at two-phase conditions. The model is based on combining single-phase

124 reactive, advective, and dispersive transport in the porous media with deposited asphaltene as a solid

125 phase. This technique has the ability to capture comprehensive picture of the interplay of the mechanisms 
Journal of Energy Resources Technology JUNE 2022, Vol. 144 / 063001-1

126 of asphaltene deposition, acid-asphaltene reaction, and acid-asphaltene sludge formation. These

127 phenomena will aid in determining the critical rate of wormhole generation around the wellbore for

128 maximum permeability enhancement. Figure 1 shows the flowchart followed for asphaltene based

129 wormhole penetration modeling describing how the study is conducted. The 1D developed model

130 incorporates the rock-acid-asphaltene interactions in the following sequence: i) deposition of asphaltene ii)

131 diffusion of acid in the immediate wellbore vicinity of rock-asphaltene interface, iii) Surface reaction at the

132 asphaltene-formation interface between the acid and asphaltene, iv) formation of acid-asphaltene sludge

133 deposits on the rock surface and its diffusion away from the interface.

134 Figure 2 shows the mathematical description of the developed model for asphaltene based

135 wormhole penetration modeling. In this study, it was assumed that light and heavy oil components are

136 produced, the oil residue (asphaltene) is deposited in the reservoir, capillary and gravity forces are

137 negligible, and the temperature of the reservoir is constant during acid injection.

138 Fluid Flow in Porous Media. The single-phase model is extended to a two-phase formulation for fluid flow

139 in porous media. Thus, Darcy's law is used, as it is the fundamental equation for fluid-flow in porous media

140 where the phase flow is given by:

$141 \frac{\partial \phi}{\partial t}+\nabla \cdot v_{t}=0$

142 where $\phi$ is formation porosity, $\mathrm{t}$ is time, and $v_{t}$ is velocity of all the phases present in the porous media 143 including water and oil.

144 The acid-rock surface reaction rate could be determined by calculating acid mass transfer from the 145 bulk acid-water solution to the rock surface. This technique helps in finding the sequential rate of acid 146 concentration on the rock surface interface from the bulk acid-water solution. Therefore, the rate of mass

147 transfer from the bulk solution to the rock surface interface could be determined as:

$148 \mathrm{Fr}_{\mathrm{r}}=\mathrm{km}_{\mathrm{m}}\left(\mathrm{C}_{\mathrm{ac}}-\mathrm{C}_{\mathrm{rf}}\right)$,

149 where $F_{r}$ is the rate of bulk fluid mass transfer from the bulk fluid to the rock surface interface, $\mathrm{k}_{\mathrm{m}}$ is the 150 mass transfer-coefficient, $C_{a c}$ is concentration of acid in the aqueous phase, and $C_{r f}$ is concentration of acid 151 at rock-fluid interface. 
Journal of Energy Resources Technology JUNE 2022, Vol. 144 / 063001-1

152 Asphaltene Deposition Model. Among different organic matters present in the crude oil, asphaltenes are

153 the most complex mixture of colloidal suspended molecular particles with no certain chemical formula [50].

154 Consequently, due to different aggregate sizes, asphaltenes have a wide range of molecular weights from

$1551,650-500,000 \mathrm{~g} / \mathrm{mol}$ [52]. To study the behavior of precipitation and deposition of asphaltene during

156 production and other enhanced oil recovery operation, the asphaltene onset pressure is the most important

157 factor. This onset pressure is determined by using a mixture of reservoir fluids at varying percentage of

158 injected fluid in the reservoir. However, this technique only addresses the static asphaltene behavior and

159 thus, the risk of asphaltene deposition under dynamic conditions is ignored.

160 To encounter this issue, dynamic asphaltene behavior is used to have a clear picture of asphaltene

161 deposition in oil recovery operations. Thus, dynamic behavior shows that when asphaltene deposits in the

162 pores of the reservoir, the reservoir fluid loses its heavy components. This process causes a reverse

163 phenomenon where the density of live oil increases and that of dead oil decreases. In a giant oil field in the

164 Middle East, the density of dead oil was $0.805 \mathrm{~g} / \mathrm{cm}^{3}$ and that of the produced oil was in the range of 0.83 -

$1650.84 \mathrm{~g} / \mathrm{cm}^{3}$ [53]. This reverse-density phenomenon indicates that with the continuous oil production and

166 associated reservoir pressure drop, the equilibrium of reservoir fluids is disturbed and due to gravity

167 segregation, the heavy oil component (asphaltene) is deposited in the reservoir. The risk of asphaltene

168 deposition is even more severe in case of light crudes, when the reservoir fluids are in a highly under-

169 saturated reservoir pressure [41]. When acid is injected in the porous media, its flow is described by the

170 continuity equation as follows:

171

$\frac{\partial}{\partial t}\left(S_{l} \rho_{a s} X_{a s} \phi+S_{l} \rho_{l} w_{a s} \phi\right)=-\left(\rho_{a s} \frac{\partial V_{a s}}{\partial t}+\frac{\partial}{\partial r}\left(\rho_{l} w_{a s p} v_{l}+\rho_{l} w_{a s} v_{l}\right)\right)$.

172 where $S$ is saturation in fraction, $\rho$ is density in $\mathrm{kg} / \mathrm{m}^{3}, \mathrm{X}$ is asphaltene concentration, $\phi$ is porosity in fraction,

$173 v$ is fluid flow in $\mathrm{m} / \mathrm{s}, w$ is mole concentration, $v$ is deposited concentration, and $t$ is time in s. Subscripts $a$,

$174 \quad o, l, g$, as, and asp refer to aqueous, oil, liquid, gas, asphaltene, and suspended asphaltene, respectively.

175 One should note that further details can be found in Appendix A.

176 For asphaltene deposition, several researchers have performed experimental and simulation

177 studies to determine the risk of asphaltene deposition. Gruesback and Collins observed that the deposition 
Journal of Energy Resources Technology JUNE 2022, Vol. 144 / 063001-1

178 of asphaltene is dependent on the concentration of asphaltene in the reservoir fluid [54]. Thus, they derived

179 a simple model by considering a single-phase flow. Wang and Civan [55] considered some complexities and

180 showed that asphaltene deposition is controlled by its concentration in the reservoir fluid, deposition

181 behavior, trapping, and plugging mechanism in the porous media. They mentioned that the observed

182 plugging of the pore throat is related to asphaltene concentration, liquid saturation, superficial velocity,

183 and gravity segregation. They derived the following equation:

$184 \frac{\partial \eta_{a s}}{\partial t}+\left(v_{l}-v_{c r . l}\right) d_{a s} \beta_{a s}=S_{l} \alpha_{a s} C_{a s} \phi+S_{l} \gamma v_{l} C_{a s}$,

185 where $\eta_{a s}$ is deposition rate of asphaltene, $v_{l}$ is interstitial velocity, $d_{a s}$ is asphaltene deposition rate, $B_{a s}$ is 186 asphaltene entrainment rate coefficient, $S_{I}$ is saturation of liquid, $\alpha_{a s}$ is coefficient of asphaltene surface 187 deposition, $\gamma$ is plugging coefficient, and $C_{a s}$ is asphaltene concentration. Therefore, the precipitation and 188 deposition of asphaltene on porous rock surfaces could lead to severe formation damage, pore blockage, 189 and reservoir relative permeability impairment [56]. The deposition of asphaltene on a rock surface is 190 controlled by two mechanisms; mass transfer and chemical reactions for flocs appearance, precipitation, 191 and deposition of asphaltene. Afra et al. mentioned that during $\mathrm{CO}_{2}$ injection, the injected $\mathrm{CO}_{2}$ reacts with 192 the amine functional group of asphaltene [57]. This reaction decreases the stability of asphaltene in the oil 193 and thus, asphaltene could be destabilized through physical interactions and chemical reactions.

194 Soulgani et al. performed several experiments for asphaltene deposition and observed the 195 deposition of asphaltene decreased as soon the injected fluid velocity is increased [58]. This phenomenon 196 shows that mass transfer is a less controlling mechanism. It was also found that when temperature 197 increases, the heat transfer coefficient decreases at a higher rate, which promotes asphaltene deposition.

198 This behavior of asphaltene shows that asphaltene deposition is controlled by temperature of the system.

199 Therefore, chemical reaction is the determining mechanism of asphaltene deposition. A number of 200 researchers developed different models and investigated asphaltene [58-62]. However, it was found that 201 the deposition of asphaltene is controlled by chemical interactions of injected fluid and oil. Therefore, in 202 this work, the deposition of asphaltene in the porous media was estimated by the asphaltene deposition 203 model in Equation (5) and was added with Equation (4) to estimate the net asphaltene deposition volume 
Journal of Energy Resources Technology JUNE 2022, Vol. 144 / 063001-1

204 fraction that will deposit in the reservoir. Different coefficients for asphaltene deposition could be found in

205 Table 1.

$206 \frac{\partial \omega_{a s}}{\partial t}=K \frac{C_{a s}}{v} e^{-E / R T}$,

207 where $\omega$ is rate of asphaltene deposition per unit time, $\chi$ is reaction rate coefficient, $C$ is concentration, $E$ is

208 activation energy, $\mathrm{R}$ is universal gas constant, $\mathrm{T}$ is reservoir temperature, and $v$ is acid flow rate. The

209 subscript "as" stands for asphaltene.

210 Capturing Changes in Porosity and Permeability. After the deposition of asphaltene, the reservoir rock

211 surface area will be modified. This deposition would decrease the reservoir permeability. Thus, changes in

212 reservoir permeability were captured in the model through updating reservoir porosity and the related

213 permeability using the following equations [62]:

$214 \phi=\phi_{i}\left(1-S_{a s}\right)$,

$215 \frac{k}{k_{i}}=\left(\frac{\phi}{\phi_{i}}\right)^{e}\left(\frac{1-\phi_{i}}{1-\phi}\right)^{2}$,

216 where $k$ is reservoir permeability, $\phi$ is reservoir porosity, $\mathrm{S}$ is saturation, and subscripts $i$ and as represent

217 the initial stage and asphaltene, respectively. The exponent $e$ with values of 3,5 , and 12 represent clean

218 formations, anhydrite precipitation, and for coreflooding experiments showing the technical time scale for

219 anhydrite dissolution and precipitation, respectively. It should be noted that an $e$ value of 3 was used in this

220 work. This is because of the assumption that the carbonate formation is clean without clay, which is usually

221 the case. In addition, it was assumed that the rock is $100 \%$ calcite in this study and the effects of

222 dissolution/precipitation of other solid species were not considered as it requires a comprehensive

223 geochemical engine.

224 Sludge Formation Model. After acid injection, insoluble organic precipitate, known as acid-asphaltene

225 sludge, is formed [49]. This sludge is too sticky and is highly undesirable type of formation damage, which

226 could adversely affect the whole acid job. The formed acid-asphaltene flocs has the tendency to form acid-

227 asphaltene aggregates leading to the formation of acid-asphaltene sludge. This is due to the charged groups

228 present on asphaltene boundary, which demonstrates the sticky mass of sludge formed at the acid- 
Journal of Energy Resources Technology JUNE 2022, Vol. 144 / 063001-1

229 asphaltene interface. It was assumed that the formation of sludge will hinder the direct contact of acid with

230 the rock. Thus, the acid transfer from the aqueous phase to the solid asphalt phase is described by [49]:

$231 \omega_{a s}+H C_{a q} \underset{k_{-1}}{\stackrel{k_{1}}{\rightleftarrows}} \omega H^{+} C_{a s}^{-}$,

232 where HC represents acid, subscript "aq" stands for aqueous, " $k$ " coefficient is phase transport, and

$233 \mathrm{XH}^{+} \mathrm{C}_{a s}^{-}$is the formed acid-asphaltene sludge term abbreviated as $Y_{a s}$ and is represented by:

$234 \quad \omega H^{+} C_{a s}^{-} \underset{k_{-2}}{\stackrel{k_{2}}{\rightleftarrows}} Y_{a s}$.

235 After combining Equations (8) and (9), the rate of acid-asphaltene sludge formation is given by:

$236 \frac{d Y_{a s}}{d t}=k_{2}\left[\omega H^{+} C_{a s}^{-}\right]-k_{-2}[Y]_{a s}$.

237 The concentration of acid is also considered constant at a certain time and it increases with acid injection.

238 Thus, the boundary condition for acid-asphaltene sludge formed at initial time ( $\mathrm{t}$ is zero) is given by:

$239 \frac{d Y_{a s}}{d t}=k_{1} \omega_{a s} H C_{a q} V$.

240 Modified Wormhole Propagation Model. Based on Equation (11), the rate of acid-asphaltene sludge

241 formation is proportional to the concentration of phase transport by asphaltene, the acid activity in

242 aqueous phase, and its volume. Economides et al. assumed that for wormholing, the injected acid would

243 dissolve a certain volume of rock to penetrate in the formation [9]. They used this approach to determine

244 the acid volume to predict the distance of wormhole penetration. It was observed that the dissolution of

245 small rock fragments will form few wormholes while the dissolution of large rock fraction will create more

246 branched and deep wormholes in the rock matrix. They proposed an equation for rock acidization by

247 injected acid as follows [9]:

$248 \quad r_{w o}=\sqrt{r_{r}+\frac{N_{c} V}{\pi \phi h \tau}}$,

249 where $r_{w o}$ is radial wormhole penetration in feet, $r_{r}$ is wellbore radius in feet, $N_{c}$ is acid capacity number

250 that is defined by the ratio of amount of rock mineral dissolved by the injected acid to the amount of rock

251 mineral present in a unit rock volume, $V$ is the acid volume in cubic feet, $h$ is the reservoir height in feet,

252 and $\tau$ is wormholing efficiency that is estimated from coreflooding. The wormholing efficiency depends on 
Journal of Energy Resources Technology JUNE 2022, Vol. 144 / 063001-1

253 acid capacity number and number of acid pore volume injected until breakthrough [10]. However, this

254 model has a couple of constraints; it overlooks fluid loss, reaction with organic matter present in crude oil,

255 and asphaltene deposition in the porous media. Ignoring these factors over predicts the depth of wormhole

256 penetration. Equation (13) is the proposed modified model, which was derived by deducting Equation (11)

257 from Equation (12) to formulate the net reaction of acid-asphaltene sludge formation that will occur in the

258 reservoir.

$259 r_{w o}=\sqrt{r_{r}+\frac{N_{c} V-k_{1} \omega_{a s} H C_{a q} V}{\pi \phi h \tau}}$.

260 Table 1 provides the values of the different variables used in this study. The data for wormholing

261 efficiency and its propagation with strong acid in core samples were taken from Furui et al. [38]. The rock

262 is carbonate and the acid is hydrochloric acid as mentioned by Furui et al. [38]. Economides et al. mentioned

263 that the wormhole efficiency can be estimated from the data of a linear coreflooding, and is given by [1]:

$264 \tau=N_{c} \times P V$,

265 where PV is the pore volume of the acid injected at the time of wormhole breakthrough at the end of the

266 core. In order to determine the rate of acid-asphaltene sludge formation in the initial stage of reaction, the

267 concentration of asphaltene was assumed to be constant and the reverse reactions in Equations (8) and (9)

268 were neglected. The objective of this study is to evaluate the effect of organic matter present in reservoir

269 oil on wormholing, by combining acid-formation reaction and acid-organic matter reaction to the formation

270 of acid-asphaltene sludge. Figure 3 shows a graphical representation of acidization with and without

271 asphaltene, creation of acid-asphaltene sludge, and aggregation of sludge to acid-asphaltene sludge in the

272 porous media.

273 During the development of the acid-asphaltene sludge model, the main objective is to define

274 formation damage. Unfortunately, very limited experimental research is conducted on wormholing in

275 asphaltene deposited cores. Nevertheless, Kumar et al. [47] investigated acidization of both brine saturated

276 and residual oil saturated cores as shown in Figures 4 (i) and (ii), respectively. The findings of Kumar et al.

277 [47] showed that the organic layer acts as a physical wall or barrier between acid and rock and thus,

278 validates the concept/technique presented in this paper. Therefore, the results generated are more realistic 
Journal of Energy Resources Technology JUNE 2022, Vol. 144 / 063001-1

279 where the formation of acid-asphaltene sludge reduces acid-rock reaction and further hinders wormhole

280 penetration. As was previously mentioned, this fundamental fact is usually ignored leading to large

281 discrepancies between simulation and field data [38].

282 DEVELOPED MODEL VALIDATION. In modeling acid-asphaltene sludge formation, it was observed that the 283 most difficult part is to model the deposition of asphaltene. This is because in acidization, the injected acid

284 is usually very strong and it will definitely react, but determining asphaltene deposition is complex.

285 Asphaltene deposition is controlled by rock properties, formation water composition, oil properties,

286 thermodynamic conditions of the reservoir, and flow rate of the injected fluids. To validate the developed

287 numerical model, the experimental work conducted by Soulgani et al. [58] was used. In the latter 288 experimental work, the authors used coreflooding to determine the formation damage caused by 289 asphaltene deposition. The details of experimental run are given in Table 1.

$290 \quad$ Figure 5 presents a good match between the experimental data and our simulation results. One 291 should note that the observed asphaltene deposition has adverse effects on formation permeability and

292 acid is usually injected to recover this permeability. It is evident from Figure 5 that with the increase in 293 injected pore volumes, the formation damage increases. The formation damage is presented by the 294 permeability ratio of altered to initial permeability. Furthermore, one can observe from the latter figure 295 that due to asphaltene deposition, the reservoir permeability decreased by $46 \%$. This decrease will certainly

296 have a negative effect on oil production from a reservoir. Moreover, data from experiments conducted by 297 different researchers were used to further evaluate the accuracy of the developed model. Figure 6 shows

298 a good match with Bagheri et al. [63]. In the latter study, the authors performed experimental investigation

299 of asphaltene precipitation and deposition process during different production schemes such as natural

300 depletion, lean gas injection, and $\mathrm{CO}_{2}$ injection. The simulation results of this work were compared with

301 their $\mathrm{CO}_{2}$ injection case because $\mathrm{CO}_{2}$ forms a weak acid in the reservoir by mixing with formation water.

302 More details about their experimental work are described elsewhere [63]. Further explanation on the

303 asphaltene deposition and acid-asphaltene sludge formation will be discussed in the results and discussion

304 section.

305 
Journal of Energy Resources Technology JUNE 2022, Vol. 144 / 063001-1

RESULTS AND DISCUSSION

307 After validation against the experimental data, the developed model was utilized to predict the deposition

308 of asphaltene, asphaltene-acid reaction, and acid-asphaltene sludge formation. The important factors

309 affecting wormholing that were thoroughly investigated in this work include the presence of asphaltene,

310 acid injection volume, formation temperature, formation porosity, acid concentration, and asphaltene

311 concentration. Typical values of these parameters were selected in the base case run, which represent

312 typical carbonate reservoir conditions. Table 1 shows the values of these parameters used in this study. The

313 effect of each parameter on the wormholing process is described below.

314 ASPHALTENE EFFECT. Figure 7 shows the effect of asphaltene presence on wormhole penetration. This

315 figure shows that wormhole penetration in the presence of asphaltene is slower as opposed to the absence

316 of asphaltene. In the latter figure, the wormhole penetration after $100 \mathrm{gal} / \mathrm{ft}$ of acid injection is

317 approximately $2.75 \mathrm{ft}$. Nevertheless, when asphaltene is present, the relationship between wormhole

318 penetration and volume of injected acid shows an extremely low penetration that is less than $1 \mathrm{ft}$ after

319 injecting the same amount of acid (100 gal/ft). It is worth mentioning that a monotonic increase in

320 wormhole penetration is observed with acid injection in the absence of asphaltene. However, when

321 asphaltene is present in the crude oil, the wormhole penetrates just $1 \mathrm{ft}$ with acid injection of $40 \mathrm{gal} / \mathrm{ft}$ and

322 with further acid injection, the penetration rate decreases. The reason behind this decrease in wormhole

323 penetration is the presence of asphaltene as well as formation and deposition of acid-asphaltene sludge.

324 Thus, the injected acid could not directly react with the rock matrix.

325 The acid first reacts with asphaltene, forming acid-asphaltene sludge where most of the injected

326 acid is consumed, regardless of the acid injection rate. Consequently, injecting acid in reservoirs with

327 asphaltenic crudes could lead to severe formation damage near the wellbore as evident from Figure 7. This

328 formation damage, caused by acid-asphaltene sludge, decreases the wellbore production and might

329 sometimes shut-off oil production. Therefore, acid induced asphaltene sludge will adversely affect the

330 effectiveness of wormholing.

331 ACID INJECTION VOLUME EFFECT. The effect of acid injection volume on wormholing can also be deduced 332 from Figure 7. The latter figure was produced using an acid injection at a certain acid concentration of $15 \%$ 
Journal of Energy Resources Technology JUNE 2022, Vol. 144 / 063001-1

333 by weight and asphaltene concentration that is limited to just 1 percent in the reservoir. From Figure 7, it

334 is evident that the wormhole penetrated deep in the formation when 40 gallons of acid was injected and

335 afterwards the penetration decreased. These 40 gallons of acid could be considered as an optimum acid

336 volume at which the wormhole propagation is high with minimum sludge formation. This is supported by

337 the increase of wormholing depth with increasing injected acid volume up to 40 gallons. Afterwards, any

338 further increase in injected acid volume results in a decrease in wormhole penetration.

339 These findings were not observed by Daccord et al. [9], Hung et al. [32], Buijse and Glasbergen

340 [37], and Furui et al. [38]. Because they ignored the presence of asphaltene and acid-asphaltene sludge

341 formation and considered that the wormhole propagation is proportional only to the rate of acid injection.

342 Hung et al. model [10] considered the wormhole propagation is linear while Daccord et al. model [9] showed

343 it depends on the average wormhole velocity. Moreover, both studies of Buijse and Glasbergen [37] and

344 Furui et al. [38] studies incorporated the linear relationship between acid injection rate and wormhole

345 propagation. Therefore, it is important to consider the effect of asphaltene presence in porous media during

346 wormholing; as the study shows that after a certain acid injection volume, enormous acid-asphaltene sludge

347 forms, which leads to severe formation damage and low penetration of wormhole.

348 TEMPERATURE EFFECT. The effect of temperature on wormholing in the presence of asphaltene was

349 determined as depicted in Figure 8. The latter figure mimics reservoirs with different depths of 1000, 1800,

3502600,3400 , and 4200 meters that correspond to reservoir temperatures of $40,60,80,100$, and $120^{\circ} \mathrm{C}$,

351 respectively. It is evident that the rate of wormhole penetration is high in the shallow reservoirs, which is

352 due to the exothermic reaction nature of carbonate dissolution process. The low temperature of a reservoir

353 favors dissolution reaction and results in high acid solubility. Therefore, wormholing phenomenon slows

354 down at high temperatures. Regarding the precipitation of dissolved particles, it is evident that when the

355 temperature of a reservoir is high, the process of wormholing will be low and the dissolved particles will

356 remain soluble in the media. Figure 8 illustrates that wormholing by acid injection in the presence of

357 asphaltene will be better in shallow reservoirs as opposed to deep reservoirs. Nevertheless, one should

358 carefully consider the dissolutions in the near wellbore region, which might sometimes lead to casing failure

359 and wellbore stability problems. 
Journal of Energy Resources Technology JUNE 2022, Vol. 144 / 063001-1

360 FORMATION POROSITY EFFECT. The sensitivity of formation porosity on wormholing in the presence of

361 asphaltene is shown in Figure 9. In high porous formations, the surface area of contact between acid and

362 rock surfaces is large, and the wormholing process is expected to develop more effectively than in low

363 porosity formations. However, in the presence of asphaltene, a reverse phenomenon occurs. This is because

364 acid will form acid-asphaltene sludge instead of moving deeper in the formation as shown in Figure 9. This

365 sludge might coagulate together to create a mat of acid-asphaltene sludge as shown in Figure 3 and it will

366 block acid penetration and reservoir pores/pathways. Therefore, the continuous injection of acid will

367 dissolve more rock minerals only in the near wellbore region, creating vugs around the wellbore as shown

368 in Figure 3, and the pressure drop over the acid invaded region decreases significantly.

369 Consequently, further volumes of injected acid removes some sludge and it might divert and force

370 acid flow to enter smaller pores that might give rise to the branching phenomenon. However, this branching

371 prohibits further growth of deep penetrating single-wormholes. The branching phenomenon is usually

372 intensified at higher injection volumes of acid, which might explain the start of the decreasing trend at 100

$373 \mathrm{gal} / \mathrm{ft}$ of acid injection volume for the $30 \%$ porosity curve in Figure 9 . In addition, it is evident from Figure 9

374 that for the same volume of acid injection, the wormhole penetration is deeper for low porous formations

375 than in high porous formations. It is clear from the figure that after injecting $100 \mathrm{gal} / \mathrm{ft}$ of acid, the $10 \%$

376 porosity scenario shows $2.5 \mathrm{ft}$ of wormhole penetration, while the $30 \%$ porosity scenario shows less than 1

$377 \mathrm{ft}$ of wormhole penetration. This behavior highlights that the shallow wormhole penetration is more

378 pronounced in high porous formations than low porous formations. One should note that these

379 observations hold under the assumptions of no direct acid-rock reaction, which is expected to increase the

380 formation porosity.

381 ACID CONCENTRATION EFFECT. Figure 10 illustrates the effect of acid concentration on wormhole

382 penetration. The acid might be injected in the reservoir in a number of forms such as regular acid, foamed

383 acid, and emulsified acid. These different forms might have some benefits such as foamed acid provides

384 good leak-off control and emulsified acid might have deep penetration. However, regular acid gives better

385 results at higher flow rates [47]. Therefore, a regular acid injection was utilized at different concentrations

386 of hydrochloric acid including 10,20 , and 30 percent. 
Journal of Energy Resources Technology JUNE 2022, Vol. 144 / 063001-1 a shallower wormhole penetration. This is supported from the latter figure where high acid concentration (30 percent) results in wormhole penetration of just $0.5 \mathrm{ft}$. However, a 10 percent acid solution results in wormhole penetration of more than $3 \mathrm{ft}$ at an acid injection of $100 \mathrm{gal} / \mathrm{ft}$. The reason behind this low penetration at high acid concentration is that the high acid concentration promotes sludge formation.

392 ASPHALTENE CONCENTRATION EFFECT. The effect of asphaltene concentration in reservoir fluid on

393 wormholing is presented in Figure 11. During acid injection, the reaction of acid with asphaltene depends 394 on its mixing, concentration, and solubility with the asphaltene. It could be observed from Figure 11 that 395 when asphaltene concentration is low, this creates less acid-asphaltene sludge and hence, the acid 396 penetrates deeper into the formation. This is supported by the case of 0.5 percent asphaltene (shallow 397 wormhole penetration). Moreover, the negative penetration shown in Figure 10 illustrates total pore 398 blockage by acid-asphaltene sludge formation and deposition, which halted further acid penetration as 399 supported by the case with just 1.5 percent asphaltene. Therefore, when the concentration of asphaltene 400 is high, the amount of acid-asphaltene sludge formation increases, and the penetration of acid in the 401 formation decreases. These phenomena will lead to severe and irreversible formation damage.

\section{SUMMARY AND CONCLUSIONS}

404 A numerical 1D model was successfully developed in this study to predict acid-asphaltene sludge formation 405 and its effect on wormholing during acid treatment in carbonates with asphaltenic oils. The main findings 406 of this work can be summarized as follows:

407 - The study shows for the first time that the injection of acid in carbonates with asphaltenic-oils 408 results in sludge formation that reduces the wormhole penetration from 40 percent to total pore 409 blockage as opposed to reservoirs without asphaltene deposition.

410 - The effectiveness of wormholing process is worsen by sludge formation, which was found to be 411 highly dependent on reservoir porosity, acid concentration, and solubility of asphaltene in acid. 
Journal of Energy Resources Technology JUNE 2022, Vol. 144 / 063001-1

- Shallow wormhole penetration is more pronounced in high porous formations, with less diluted acid, and in the presence of high concentration of asphaltene. The wormholing penetration is intensified by increased volume of acid injection.

- There is an optimum acid injection volume at which wormhole penetration is high and its infiltration is deep into the formation.

- It is recommended to better characterize the properties of reservoir fluid before an acid treatment job as the effectiveness of wormholing is controlled by asphaltene concentration.

419 This is the first work to discuss modeling of acid-asphaltene sludge formation and subsequent wormhole

420 development in carbonates, which is particularly important for problematic crude oils. In the future work,

421 the proposed model will be expanded to 2D and 3D, which enables capturing the branching phenomenon

422 and further validating the model against CT scan images for the wormhole.

\section{ACKNOWLEDGEMENTS}

425 The authors wish to acknowledge Khalifa University of Science and Technology in Abu Dhabi, UAE for

426 providing the computational and research facilities.

\section{APPENDIX A}

429 The flow characteristics of oil, gas, and aqueous phases are presented by the fluid flow continuity equations

430 as follows:

$431 \quad \frac{\partial\left(\rho_{o} w_{o} S_{o} \phi\right)}{\partial t}=-\frac{\partial\left(\rho_{o} w_{o} v_{o}\right)}{\partial r}$

$432 \frac{\partial\left(\rho_{g} w_{g} S_{g} \phi\right)}{\partial t}=-\frac{\partial\left(\rho_{g} w_{g} v_{g}\right)}{\partial r}$

$433 \quad \frac{\partial\left(\rho_{a} w_{a} S_{a} \phi\right)}{\partial t}=-\frac{\partial\left(\rho_{a} w_{a} v_{a}\right)}{\partial r}$

434 Combining Equations ( $A-1)$ to $(A-3)$ gives:

$435 \frac{\partial}{\partial t}\left(\rho_{o} w_{o} S_{o} \phi+\rho_{g} w_{g} S_{g} \phi+\rho_{a} w_{a} S_{a} \phi\right)=-\frac{\partial}{\partial r}\left(\rho_{o} w_{o} v_{o}+\rho_{g} w_{g} v_{g}+\rho_{a} w_{a} v_{a}\right)$ 
Journal of Energy Resources Technology JUNE 2022, Vol. 144 / 063001-1

436 For acid component, if we neglect the diffusion, the above-derived equations are given by:

$437 \frac{\partial}{\partial t}\left(\rho_{o} \omega_{w, o} S_{o} w_{o} \phi+\rho_{g} \omega_{w, g} S_{g} w_{g} \phi+\rho_{a} \omega_{w, a} S_{a} w_{a} \phi\right)=-\frac{\partial}{\partial r}\left(\rho_{o} \omega_{w, o} w_{o} v_{o}+\rho_{g} \omega_{w, g} w_{g} v_{g}+\rho_{a} \omega_{w, a} w_{a} v_{a}\right)$

438 For simplification, we assumed the acid injection rate is constant. Thus, Equation (A-5) becomes:

$$
\frac{\partial}{\partial t}\left(\rho_{o} \omega_{w, o} w_{o} S_{o}+\rho_{g} \omega_{w, g} w_{g} S_{g}+\rho_{a} \omega_{w, a} w_{a} S_{a}\right)=-\frac{q_{i n j}}{\phi} \frac{\partial}{\partial r}\left(\rho_{o} \omega_{w, o} w_{o} v_{o}+\rho_{g} \omega_{w, g} w_{g} v_{g}+\rho_{a} \omega_{w, a} w_{a} v_{a}\right)
$$

440 Therefore, during acid injection, the mass balance equation for asphaltene deposition is:

$441 \frac{\partial}{\partial t}\left(S_{l} \rho_{a s} X_{a s} \phi+S_{l} \rho_{l} w_{a s} \phi\right)=-\left(\rho_{a s} \frac{\partial V_{a s}}{\partial t}+\frac{\partial}{\partial r}\left(\rho_{l} w_{a s p} v_{l}+\rho_{l} w_{a s} v_{l}\right)\right)$

442 where $S$ is saturation in fraction, $\rho$ is density in $\mathrm{kg} / \mathrm{m}^{3}, \mathrm{X}$ is asphaltene concentration, $\phi$ is porosity in fraction,

$443 \mathrm{v}$ is fluid flow in $\mathrm{m} / \mathrm{s}, w$ is mole concentration, $V$ is deposited concentration, and $t$ is time in s. Subscripts $a$,

$444 \quad o, l, g$, as, and asp refer to aqueous, oil, liquid, gas, asphaltene, and suspended asphaltene, respectively. 


\section{NOMENCLATURE}

\section{Symbols}

A

C

$D$

d

E

$F$

$h$

K

k

L

$R$

$r$

$S$

$T$

V

v

$Y$

Greek Letters

$\phi$

w

$\rho$

$\alpha$

$b$

r

$\tau$

$\chi$

$\eta$

$\omega$

\section{Subscripts}

a

ac

as

$c$

$e$

$g$

Area of porous media, meter-square

Concentration, percentage

Coefficient of diffusion

Deposition rate, $1 / t$

Energy for activation, $\mathrm{J} / \mathrm{mol}$

Coefficient of drag force

Reservoir height, $m$

Coefficient of reaction rate

Mass transfer coefficient

Pores Length, $m$

Universal gas constant, $\mathrm{J} / \mathrm{mol} . \mathrm{K}$

Pore radius, $m$

Saturation, \%

Reservoir temperature, $K$

Volume, $\mathrm{m}^{3}$

Fluid velocity, $\mathrm{m} / \mathrm{s}$

Rate of sludge formation, $1 / t$

Formation porosity, \%

Mole concentration

Density, $\mathrm{kg} / \mathrm{m}^{3}$

Surface deposition coefficient

Entrainment rate coefficient

Plugging deposition rate coefficient

Wormholing efficiency, \%

Reaction rate coefficient

Net deposition, 1/t

Rate of asphaltene deposition per unit time

aqueous

acid

asphaltene

carbonate

exponent

gas

initial

liquid

oil

reservoir

suspension 
[1] Economides, M.J., Hill, A. D., Ehlig-Economides, Zhu, D. 2013. "Petroleum Production Systems". Pearson Education.

[2] Khurshid, I., Choe, J. 2015. "Analysis of Asphaltene Deposition, Carbonate Precipitation, and their Cementation in Depleted Reservoirs during $\mathrm{CO}_{2}$ Injection". Green hou. Gases Sci. Techn. 5, 1-11.

[3] Islam, A., Sun, A., Lu, J. 2016. "Simulating In-Zone Chemistry Changes from Injection Time to Longer Periods of CO2 Storage". Environ. Earth Sci. 75, 1346.

[4] Khurshid, I., Fujii, Y. 2021. "Geomechanical analysis of formation deformation and permeability enhancement due to low-temperature $\mathrm{CO}_{2}$ injection in subsurface oil reservoirs". J. Petrol. Explor. Prod. Tech. 11, 1915:1923.

460 [5] Na, J., Xu, T., Jiang, Z., Bao, X., Yongdong, W., Feng, B. 2016. "A Study on the Interaction of Mud Acid

[6] Al-Shalabi, E.W., Sepehrnoori, K. 2017. "Low Salinity and Engineered Water Injection for Sandstone and Carbonate Reservoirs". Gulf Professional Publishing, Elsevier, 1st Edition, Cambridge, MA, USA.

[7] Vikram, R., Rob, K. 2017. "Sustainable Shale Oil and Gas". Chapter 6-Potential for Liquid Contamination of Groundwater, Sustainable Shale Oil and Gas, Elsevier.

[8] Ejeh, C., Afgan, I., AlMansob, H., Brantson, E., Fekala, J., Odiator, M., Stanley, P., Anumah, P., Onyekperem, C., Boah, E. 2020. "Computational fluid dynamics for ameliorating oil recovery using siliconbased nanofluids and ethanol in oil-wet reservoirs". Energy Reports, 6, 3023-3035.

[9] Daccord, G., Lenormand, R., Lietard, O. 1993. "Chemical Dissolution of a Porous Medium by a Reactive Fluid-I. Model for the Wormholing" Phenomenon. Chem. Eng. Sci. 48(1), 169-178.

[10] Economides, M. J., Hill, A. D., Ehlig-Economides, C. 2008. "Petroleum Production Systems". PTR Prentice Hall, 1994.

[11] Afgan, I., Moulinec, C., Laurence. D. 2008. "Numerical simulation of generic side mirror of a car using large eddy simulation with polyhedral meshes". International journal for numerical methods in fluids 56 (8), 1107-1113.

[12] Filippone, A., Afgan, I. 2008. "Orthogonal blade-vortex interaction on a helicopter tail rotor". AIAA journal 46 (6), 1476-1489.

[13] Guleren, K. M., Afgan, I., Turan. A. 2010. "Predictions of turbulent flow for the impeller of a NASA lowspeed centrifugal compressor". Journal of Turbomachinery 132 (2).

480 [14] Han, X., Sagaut, P., Lucor, D., Afgan, I. 2012. "Stochastic response of the laminar flow past a flat plate 481 under uncertain inflow conditions". International Journal of Computational Fluid Dynamics 26 (2), 101-117.

482 [15] McNaughton, J., Rolfo, S., Apsley, D., Afgan, I., Stansby, P., Stallard, T. 2012. "CFD prediction of 483 turbulent flow on an experimental tidal stream turbine using RANS modelling". 1st Asian Wave and Tidal 484 Energy Conference, Jeju Island, Korea, 2012, Power 1 (2), 0-3.

485 [16] Afgan, I., Benhamadouche, S., Han, X., Sagaut, P., Laurence, D. 2013. "Flow over a flat plate with uniform inlet and incident coherent gusts". Journal of Fluid Mechanics 720, 457-485.

[17] Ahmed, U., Afgan, I., Apsley, D., Stallard, T., Stansby, P. 2015. "CFD simulations of a full-scale tidal turbine: comparison of les and rans with field data". 11th European Wave and Tidal Energy Conference.

[18] Wu, Z., Laurence, D., Afgan, I. 2017. "Direct numerical simulation of a low momentum round jet in channel crossflow". Nuclear Engineering and Design 313, 273-284.

[19] Wu, Z., Laurence, D., lacovides, H., Afgan, I. 2017. "Direct simulation of conjugate heat transfer of jet in channel crossflow". International Journal of Heat and Mass Transfer 110, 193-208.

[20] Abed, N., Afgan, I. 2017. "A CFD study of flow quantities and heat transfer by changing a vertical to diameter ratio and horizontal to diameter ratio in inline tube banks using URANS turbulence models". International Communications in Heat and Mass Transfer 89, 18-30.

[21] Kahil, Y., Benhamadouche, S., Berrouk, A. S., Afgan, I. 2019. "Simulation of subcritical-Reynoldsnumber flow around four cylinders in square arrangement configuration using LES". European Journal of Mechanics-B/Fluids 74, 111-122.

[22] Wu, Z., Laurence, D., Utyuzhnikov, S., Afgan, I. 2019. "Proper orthogonal decomposition and dynamic mode decomposition of jet in channel crossflow". Nuclear Engineering and Design 344, 54-68. 
Journal of Energy Resources Technology JUNE 2022, Vol. 144 / 063001-1

501

502

503

504

505

506

507

508

509

510

511

512

513

514

515

516

517

518

519

520

521

522

523

524

525

526

527

528

529

530

531

532

533

534

535

536

537

538

539

540

541

542

543

544

545

546

547

548

549

550

551

552
[23] Nguyen, PTL, Uribe, J. C., Afgan, I., Laurence, D. 2019. “A dual-grid hybrid RANS/LES model for underresolved near-wall regions and its application to heated and separating flows". Flow, Turbulence and Combustion, 1-25.

[24] Benhamadouche, S., Afgan, I., Manceau, R. 2020. "Numerical simulations of flow and heat transfer in a wall-bounded pin matrix". Flow, Turbulence and Combustion 104 (1), 19-44.

[25] Abed, N., Afgan, I., Cioncolini, A., lacovides H., Nasser, A. 2020. "Assessment and evaluation of the thermal performance of various working fluids in parabolic trough collectors of solar thermal power plants under non-uniform heat flux". Energies 13 (15), 3776.

[26] Revell, A., Afgan, I., Ali, A., Santasmasas, M., Craft, T., de Rosis, A., Holgate, J. “Coupled hybrid RANSLES research at the university of Manchester". ERCOFTAC Bulletin 120, 67.

[27] Abed, N., Afgan, I. 2020. "An extensive review of various technologies for enhancing the thermal and optical performances of parabolic trough collectors". International Journal of Energy Research 44 (7), 5117 5164.

[28] Abed, N., Afgan, I., Cioncolini, A., lacovides, H., Nasser, A., Mekhail, T. 2020. "Thermal performance evaluation of various nanofluids with non-uniform heating for parabolic trough collectors". Case Studies in Thermal Engineering 22, 100769.

[29] Ahmed, U., Apsley, D., Stallard, T., Stansby, P., Afgan, I. 2021. "Turbulent length scales and budgets of Reynolds stress-transport for open-channel flows; friction Reynolds numbers Ret = 150, 400 and 1020 ". Journal of Hydraulic Research 59 (1), 36-50.

[30] Abed, N., Afgan, I., lacovides, H., Cioncolini, A., Khurshid, I., Nasser, A. 2021. "Thermal-Hydraulic Analysis of Parabolic Trough Collectors Using Straight Conical Strip Inserts with Nanofluids". Nanomaterials $11(4), 853$.

[31] Ali, A. E. A., Afgan, I., Laurence, D., Revell, A. 2021. "A dual-mesh hybrid RANS-LES simulation of the buoyant flow in a differentially heated square cavity with an improved resolution criterion". Computers \& Fluids 224, 104949.

[32] Hung, K. M., Hill, A. D., Sepehrnoori, K. A. 1989. "Mechanistic Model of Wormhole Growth in Carbonate Matrix Acidizing and Acid Fracturing". SPE J. Petrol. Techn. 41(1), 59-66.

[33] Fredd, C. N., Fogler, H. S. 1998. "Influence of Transport and Reaction on Wormhole Formation in Porous Media". AlChE J. 44, 1933-1949.

[34] Kalia, N., Balakotaiah, V. 2007. "Modeling and Analysis of Wormhole Formation in Reactive Dissolution of Carbonate Rocks". Chem. Eng. Sci. 62, 919-928.

[35] Babaei, M., Sedighi, M. 2018. "Impact of Phase Saturation on Wormhole Formation in Rock Matrix Acidizing". Chem. Eng. Sci. 177, 39-52.

[36] Dong, K., Zhu, D., Hill, A. D. 2018. "Mechanism of Wormholing and Its Optimal Conditions: a Fundamental Explanation". J. Petrol. Sci. Eng. 169, 126-134.

[37] Buijse, M. A., Glasbergen, G. 2005. "A Semiempirical Model to Calculate Wormhole Growth in Carbonate Acidizing". Paper SPE 96892, SPE Annual Technical Conference and Exhibition, Dallas, Texas, USA.

[38] Furui, K., Burton, R. C., Burkhead, D. W., Abdelmalek, N. A., Hill, A. D., Zhu, D., Nozaki, M. 2012. “A Comprehensive Model of High-Rate Matrix-Acid Stimulation for Long Horizontal Wells in Carbonate Reservoirs: Part I-Scaling Up Core-Level Acid Wormholing to Field Treatments". SPE J. 17(1) 271-279.

[39] Ali, M. T., Nasr-El-Din, H. A. 2019. "A Robust Model to Simulate Dolomite-Matrix Acidizing”. SPE Prod \& Oper 34, 109-129.

[40] Ali, M. T., Nasr-El-Din, H. A. 2020. "New Insights into Carbonate Matrix Acidizing Treatments: A Mathematical and Experimental Study". SPE J. 25, 1272-1284.

[41] Abdollahi, R., Shadizadeh, S. R., Zargar, G. 2014. "Experimental Investigation of Acid-Induced Sludge Precipitation Using Acid Additives in Iran”. Energ. Sourc. Part A 36, 1793-1799.

[42] Tabzar, A., Fathinasab, M., Salehi, A., Bahrami, B., Mohammadi, A. H. 2018. "Multiphase flow modeling of asphaltene precipitation and deposition". Oil Gas Sci. Technol. Rev. IFP Energies nouvelles, 73, 51.

[43] Shukla, S., Zhu, D., Hill, A. D. 2006. "The Effect of Phase Saturation Conditions on Wormhole Propagation in Carbonate Acidizing". SPE J. 11. 273-281.

[44] Liu, M., Zhang, S., Mou, J., Zhou, F. 2013. "Wormhole Propagation Behavior under Reservoir Condition in Carbonate Acidizing. Transp". Porous Med. 96, 203-220. 
Journal of Energy Resources Technology JUNE 2022, Vol. 144 / 063001-1

553

554

555

556

557

558

559

560

561

562

563

564

565

566

567

568

569

570

571

572

573

574

575

576

577

578

579

580

581

582

583

584

585

586

587

588

589

590

591

592

593

594

595

596

597

598

599

600
[45] Ghommem, M., Zhao, W., Dyer, S., Qiu, X., Brady, D. 2015. “Carbonate Acidizing: Modeling, Analysis, and Characterization of Wormhole Formation and Propagation". J. Petrol. Sci. Eng. 131, 18-33.

[46] Houchin, L. R., Dunlap, D. D., Arnold, B. D., Domke, K. M. 1990. "The Occurrence and Control of Acidinduced Asphaltene sludge". Paper SPE 19419, SPE Formation Damage Control Symposium, Lafayette, Louisiana, USA, 1990.

[47] Kumar, R., He, J., Nasr-El-Din, H. 2014. "New Insights on the Effect of Oil Saturation on the Optimal Acid-Injection Rate in Carbonate Acidizing". Paper SPE 169134, SPE Improved Oil Recovery Symposium, Tulsa, Oklahoma, USA.

[48] AlMubarak, T., AlKhaldi, M., AlMubarak, M., Rafie, M., Al-lbrahim, H., AlBokhari, N. 2015. "Investigation of Acid-Induced Emulsion and Asphaltene Precipitation in Low Permeability Carbonate Reservoirs". Paper SPE 178034, SPE Saudi Arabia Section Annual Technical Symposium and Exhibition, AlKhobar, Saudi Arabia.

[49] Rietjens, M., Van Haasterecht, M. 2003. “Phase Transport of $\mathrm{HCl}, \mathrm{HFeCl} 4$, Water, and Crude Oil Components in Acid-Crude Oil Systems". J. Collo. Interf. Sci. 268 (2), 489-500.

[50] Alrashidi, H., Ibrahim, A. F., Nasr-El-Din, H. A. 2018. "Bio-Oil Dispersants Effectiveness on Asphaltene Sludge During Carbonate Acidizing Treatment". Paper SPE 191165, SPE Trinidad and Tobago Section Energy Resources Conference, Port of Spain, Trinidad and Tobago.

[51] Civan, F. 2016. "Reservoir Formation Damage Fundamentals, Modeling, Assessment, and Mitigation". Third edition, Gulf Publishing Company, Houston, Texas.

[52] Mullins, O. C., Sheu, E. Y., Hammam, I. A., Marshall, A. G. 2007. "Asphaltenes, Heavy Oils, and Petroelomics". Springer, New York City, USA.

[53] Yonebayashi, H., Al Mutairi, A. M., Al Habshi, A. M., Urasaki, D. 2011. "Dynamic Asphaltene Behavior for Gas-Injection Risk Analysis". SPE Reser. Evalu. Eng. J. 14 (4), 493-504.

[54] Gruesbeck, C., Collins, R. E. 1982. "Entrainment of Deposition of Fine particles in Porous media". SPE J. 22 (6) (1982), 847-856.

[55] Wang, S., Civan, F. 2001. “Productivity decline of vertical and horizontal wells by asphaltene deposition in petroleum reservoirs". Paper SPE 64991, SPE International Symposium on Oilfield chemistry, Houston, Texas, USA.

[56] Mehana, M., Abraham, J., Fahes, M. 2019. "The Impact of Asphaltene Deposition on Fluid Flow in Sandstone". J. Petrol. Sci. Eng. 174, 676-681.

[57] Afra, S., Samouei, H., Golshahi, N., Nasr-El-Din, H. 2020. "Alterations of Asphaltene Chemical structure due to Carbon dioxide Injection". Fuel 272, 117708.

[58] Soulgani, S. B.,Tohidi, B., Ahmadi, J. M., Rashtchian, D. 2011. "Modeling Formation Damage due to Asphaltene Deposition in the Porous Media". Energy \& Fuels 25, 753-761.

[59] Almehaideb, R. A. 2004. "Asphaltene Precipitation and Deposition in the near wellbore region: a modeling approach". J. Pet. Sci. Eng. 42, 157-170.

[60] Yaseen, S., Mansoori, G. A. 2018. “Asphaltene Aggregation due to Waterflooding (A Molecular Dynamics Study)". J. Petro. Sci. Eng. 170, 177-183.

[61] Khurshid, I., Choe, J. 2018. "Analysis of Thermal Disturbance and Formation damage during $\mathrm{CO}_{2}$ Injection in shallow and deep reservoirs". Int. J. Oil Gas Coal Techn. 11(2), 141-153.

[62] Khurshid, I., Al-Shalabi, E. W., Al-Attar, H., Al-Neaimi, A. K. 2020. "Analysis of Formation Damage and Fracture Choking in Hydraulically Induced Fractured Reservoirs due to Asphaltene Deposition". Journal of Petroleum Exploration and Production Technology, 173.

[63] Bagheri, M. B., Kharrat, R., Ghotby, C. 2011. "Experimental Investigation of the Asphaltene Deposition Process during Different Production Schemes". Oil Gas Sci. Techn. 66(3), 507-519. 
Journal of Energy Resources Technology JUNE 2022, Vol. 144 / 063001-1

601

602

603

604 
Journal of Energy Resources Technology JUNE 2022, Vol. 144 / 063001-1

605

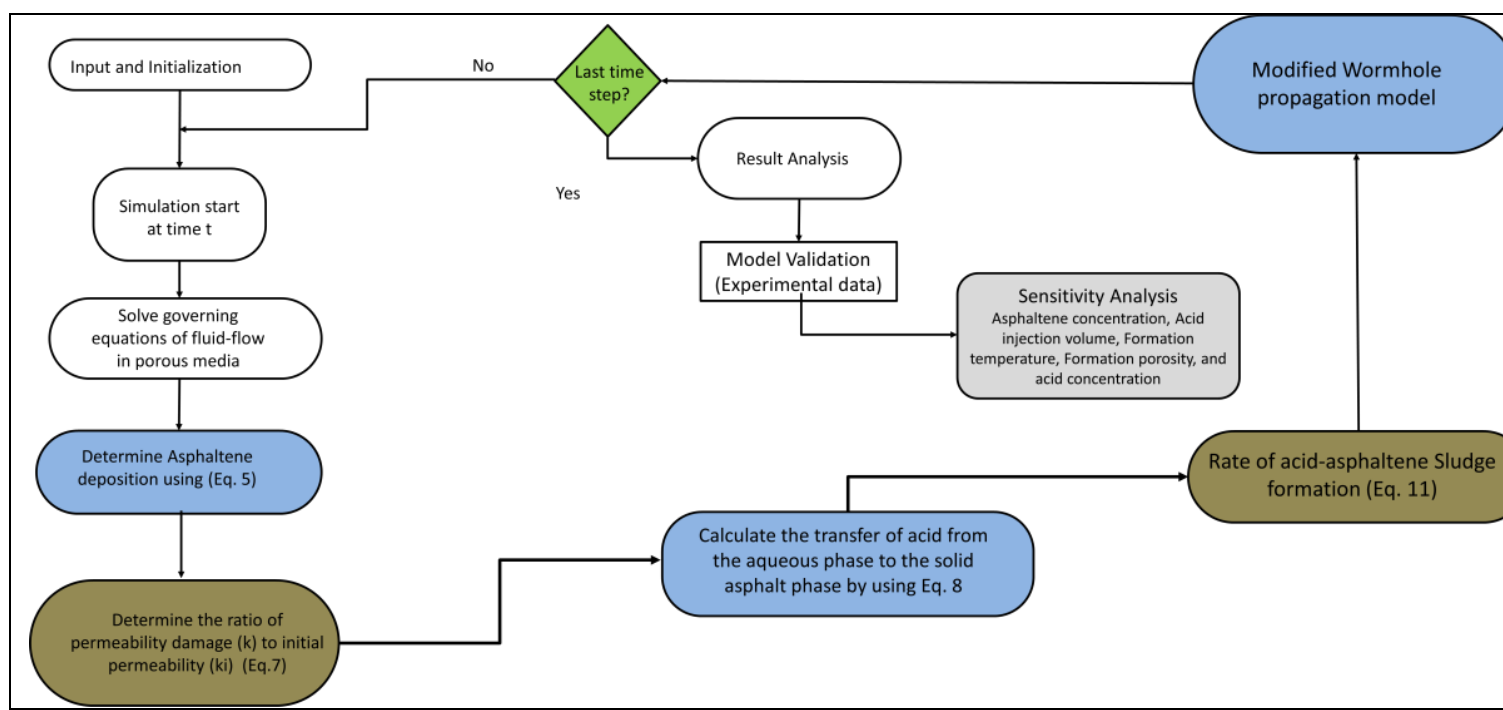

Fig. 2 Mathematical description of the developed model for asphaltene based wormhole penetration modeling

606

607

608

609 
Journal of Energy Resources Technology JUNE 2022, Vol. 144 / 063001-1

610

611

612

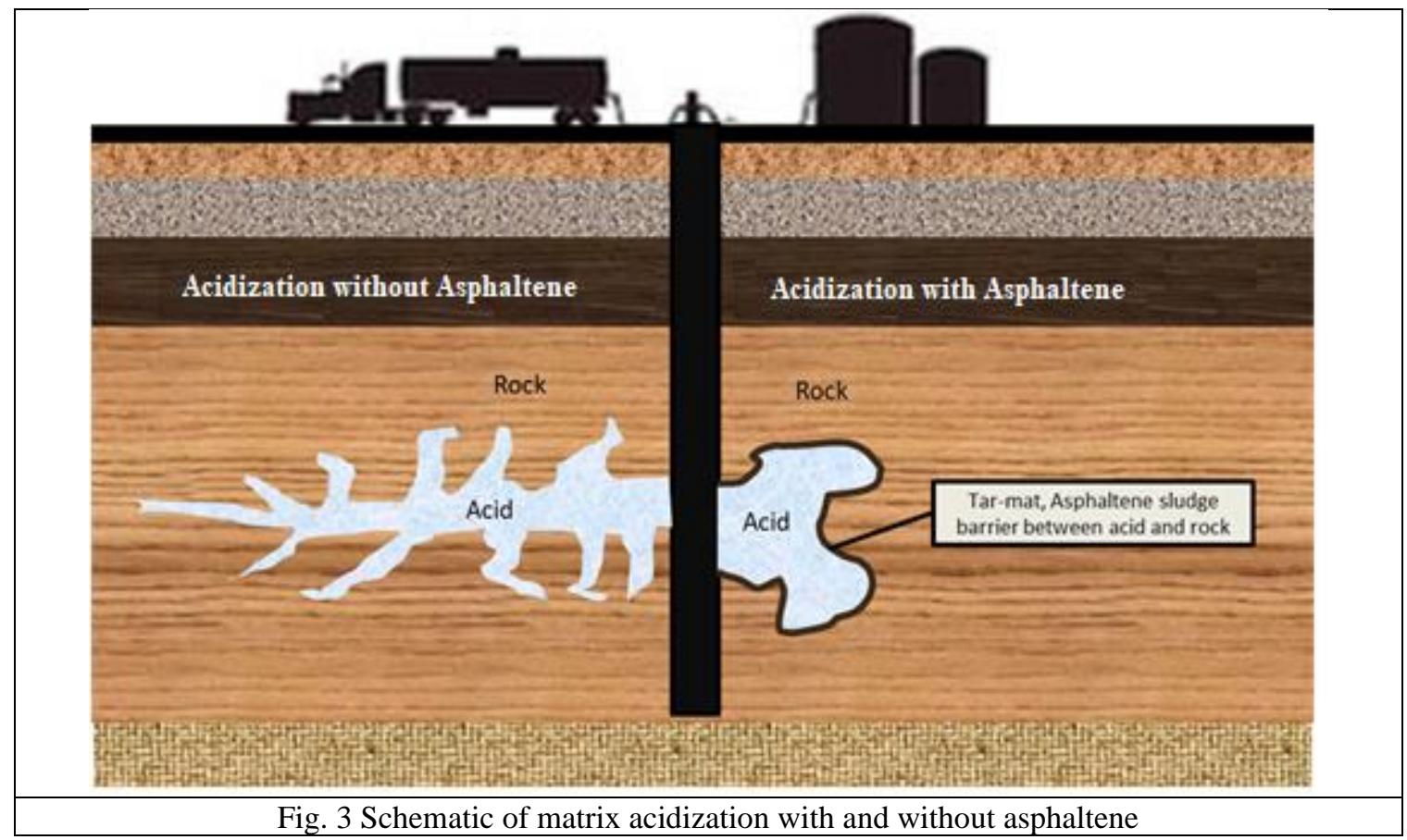

613

614 
Journal of Energy Resources Technology JUNE 2022, Vol. 144 / 063001-1

615

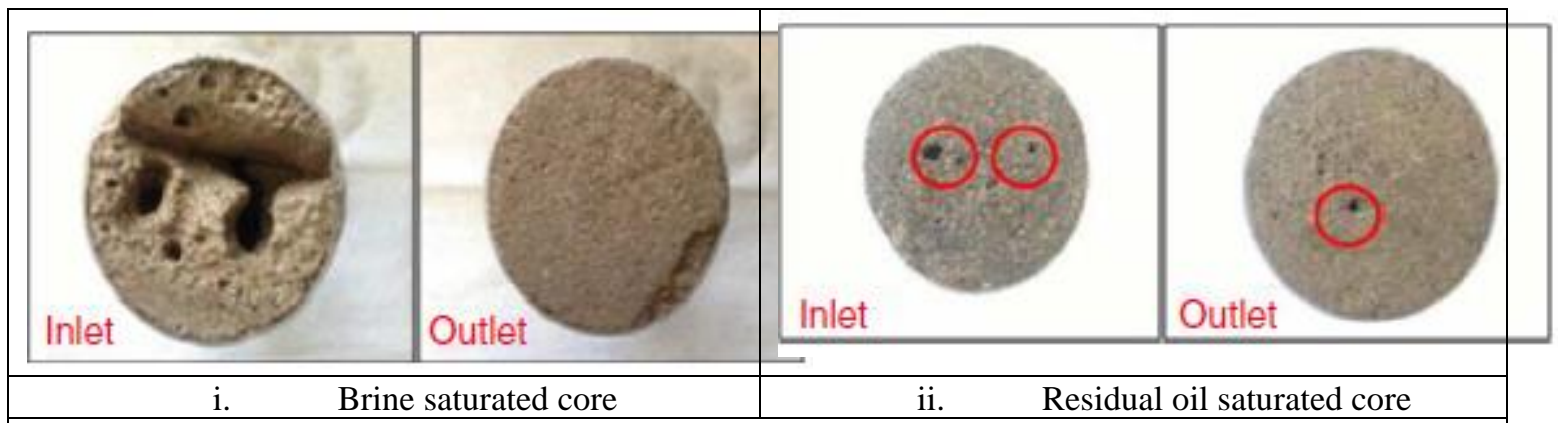

Fig. 4 Comparison of inlet and outlet faces of the 6-inch limestone cores with $15 \mathrm{wt}$ \% $\mathrm{HCl}$ injection at $5 \times 10^{-7} \mathrm{~m}^{3} / \mathrm{min}$ and $93.3^{\circ} \mathrm{C}[25]$

616

617 
Journal of Energy Resources Technology JUNE 2022, Vol. 144 / 063001-1

618

619

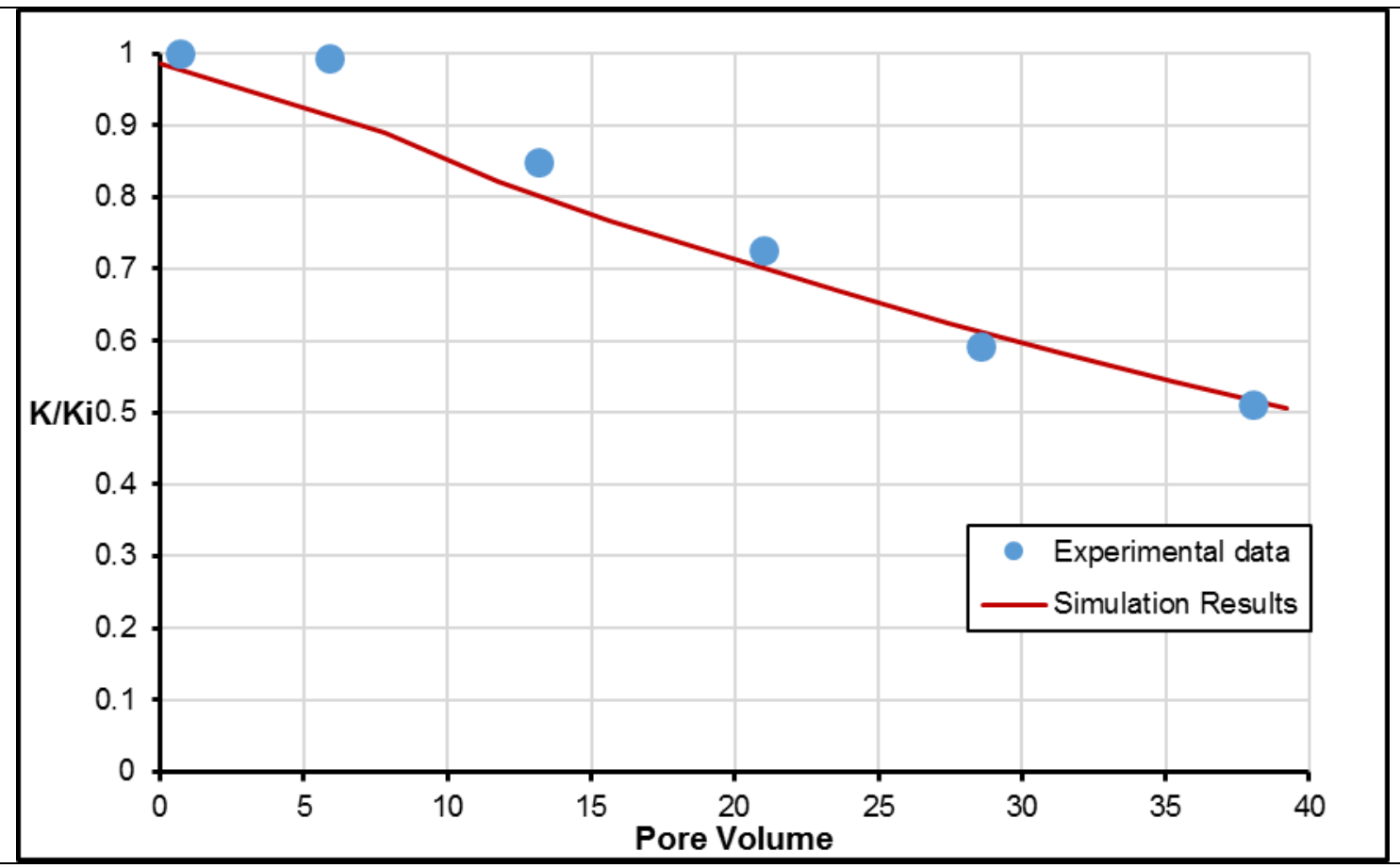

Fig. 5 Comparison of simulation results with experimental data perfomred at $2.76 \times 10^{-9} \mathrm{~m}^{3} / \mathrm{s}$ and $80{ }^{\circ} \mathrm{C}$ [36] 
Journal of Energy Resources Technology JUNE 2022, Vol. 144 / 063001-1

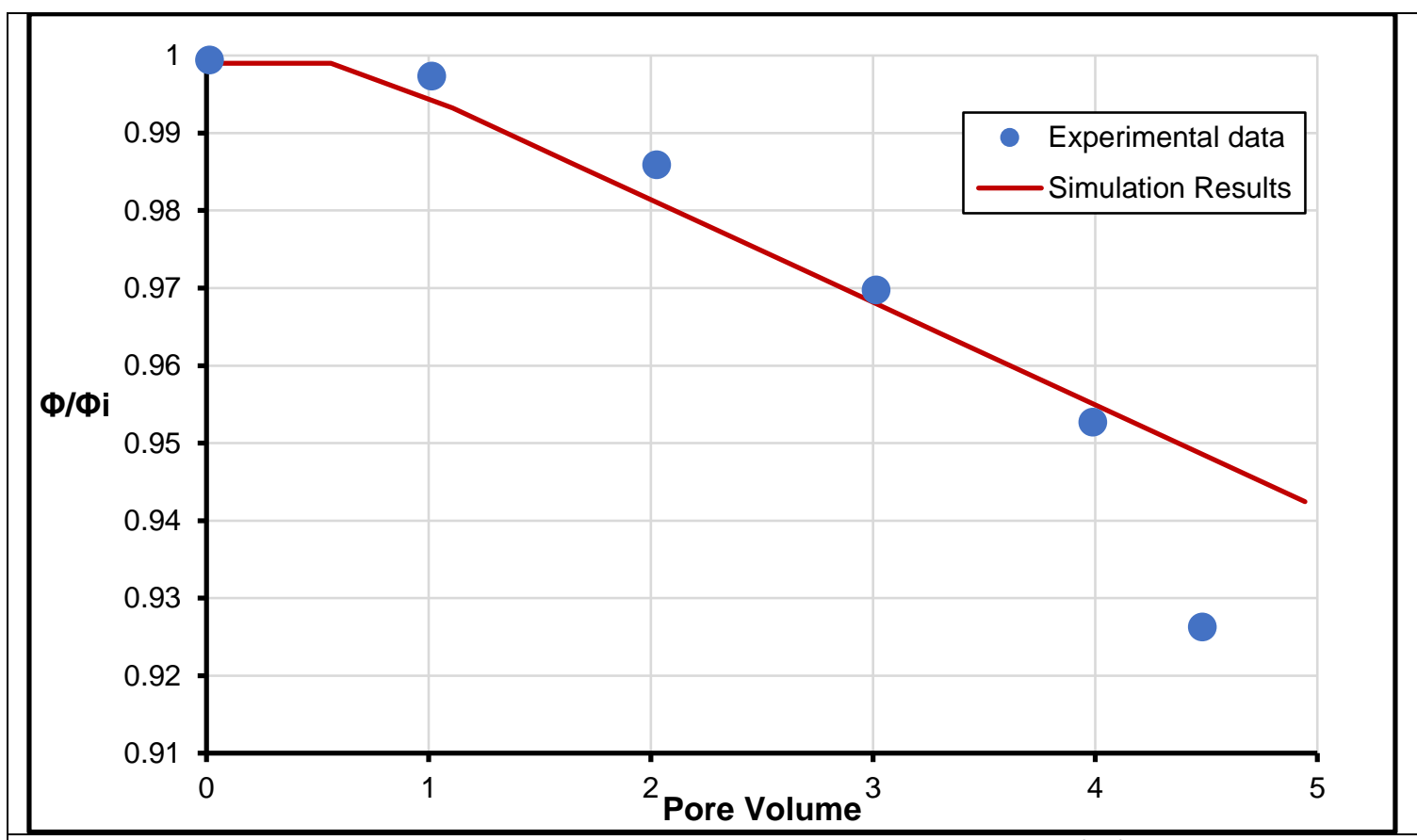

Fig. 6 Comparison of results with experimental data perfomred at $1.33 \times 10^{-8} \mathrm{~m}^{3} / \mathrm{s}$ and $96^{\circ} \mathrm{C}$ [41] 
Journal of Energy Resources Technology JUNE 2022, Vol. 144 / 063001-1

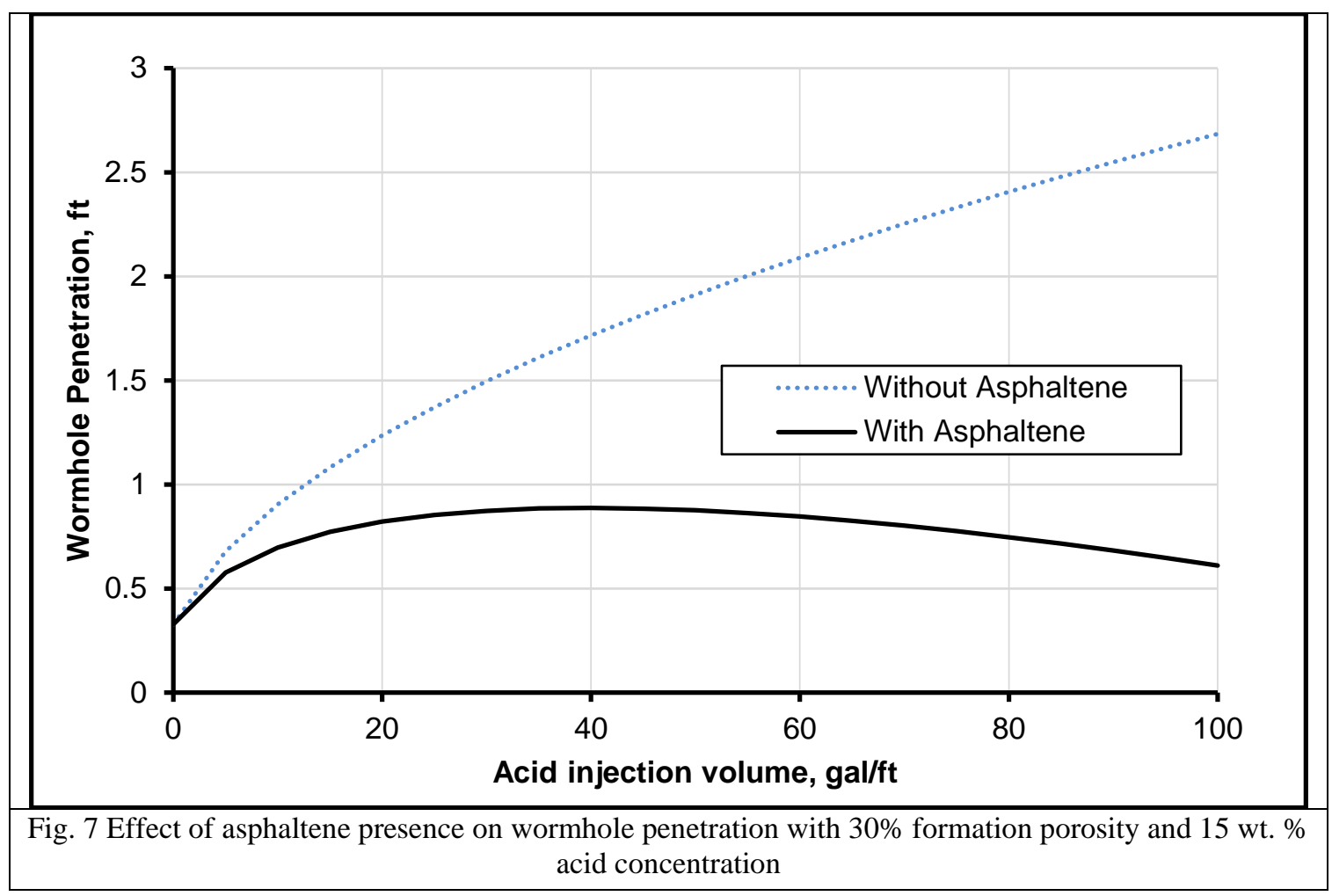

629

630 
Journal of Energy Resources Technology JUNE 2022, Vol. 144 / 063001-1

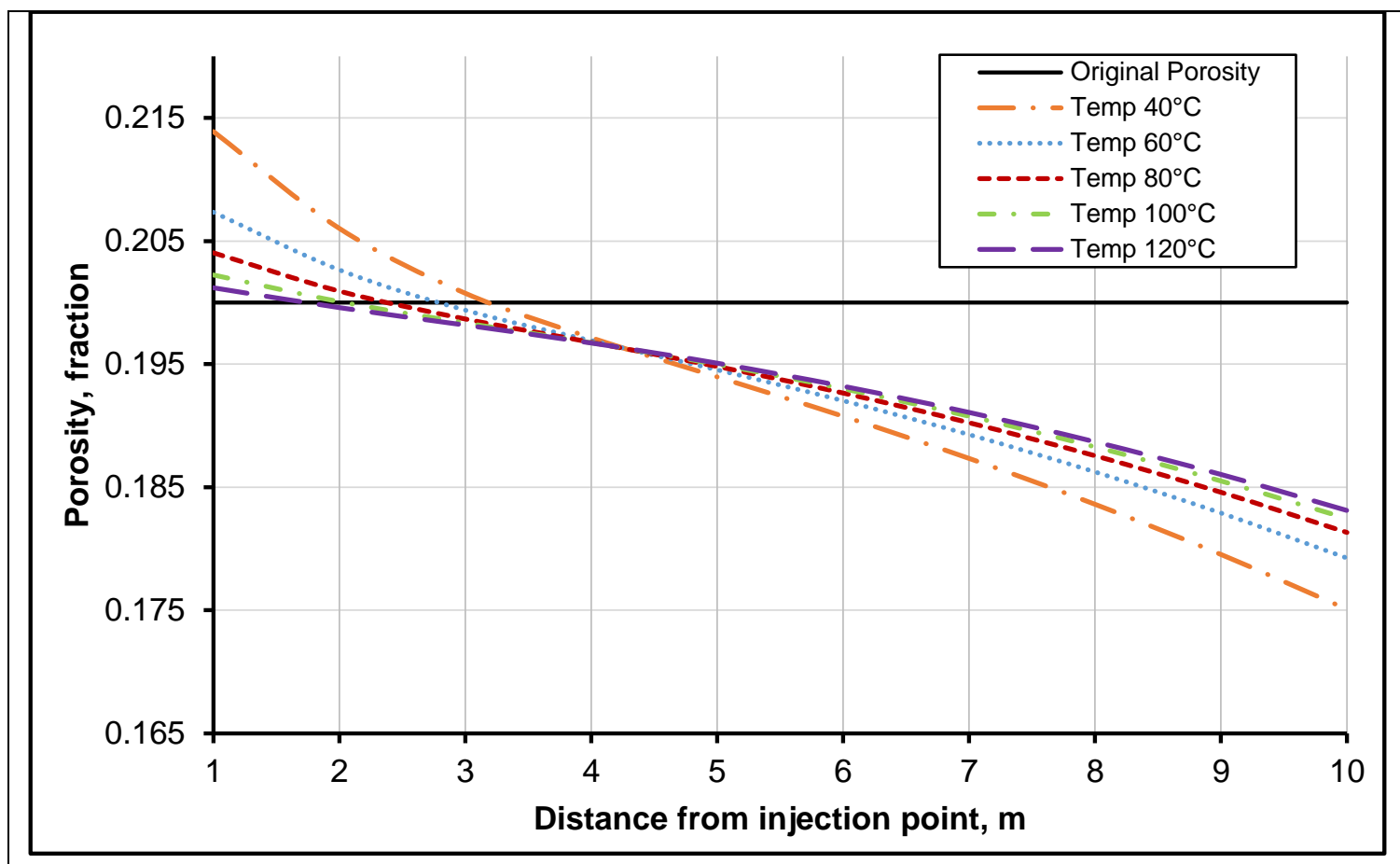

Fig. 8 Effect of temperature on wormhole penetration in the presence of $5.3 \mathrm{wt} . \%$ asphaltene and $30 \%$ formation porosity 
Journal of Energy Resources Technology JUNE 2022, Vol. 144 / 063001-1

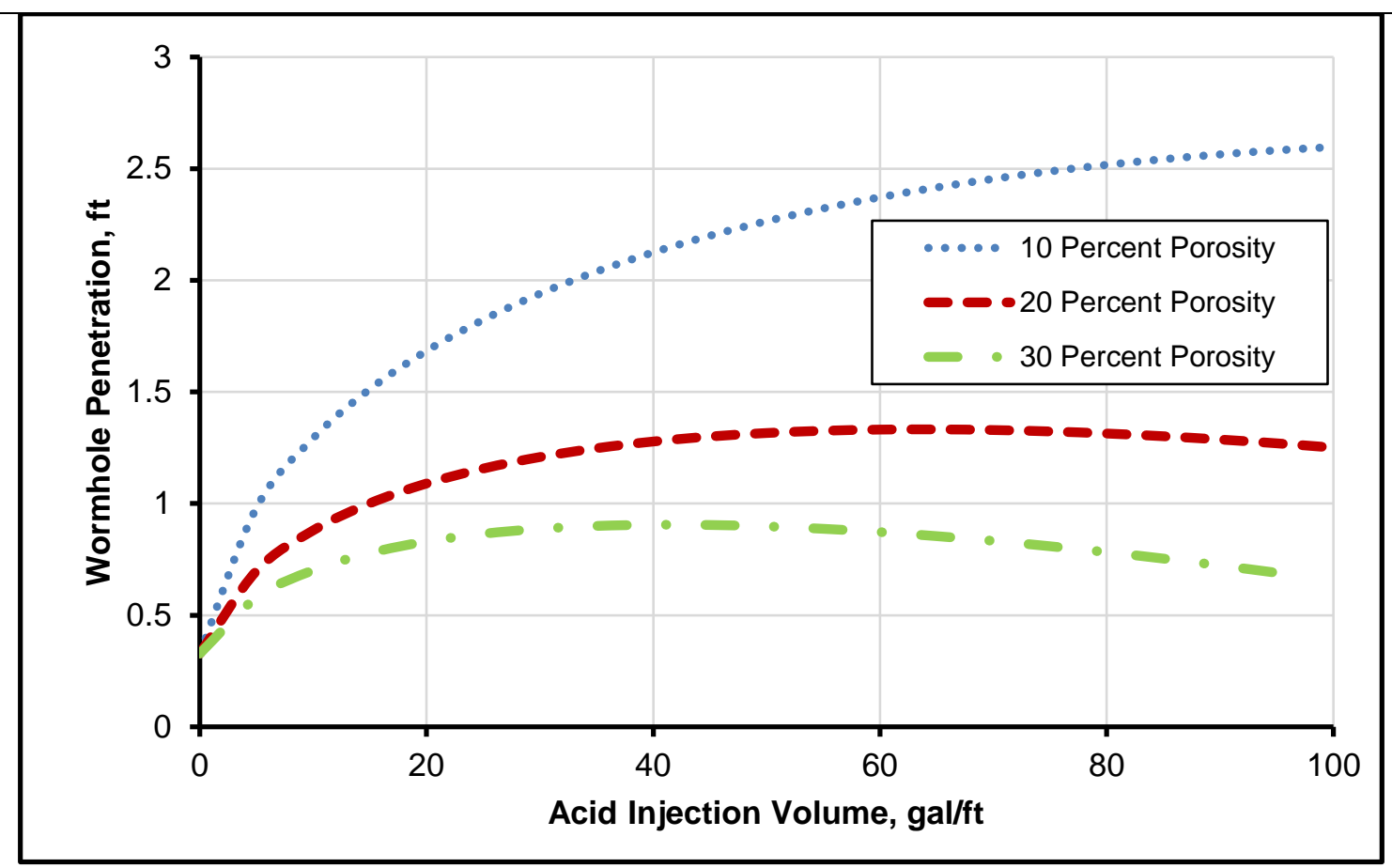

Fig. 9 Effect of formation porosity on wormholing in the presence of $5.3 \mathrm{wt} . \%$ asphaltene and $15 \mathrm{wt} . \%$ acid concentration 
Journal of Energy Resources Technology JUNE 2022, Vol. 144 / 063001-1

635

636

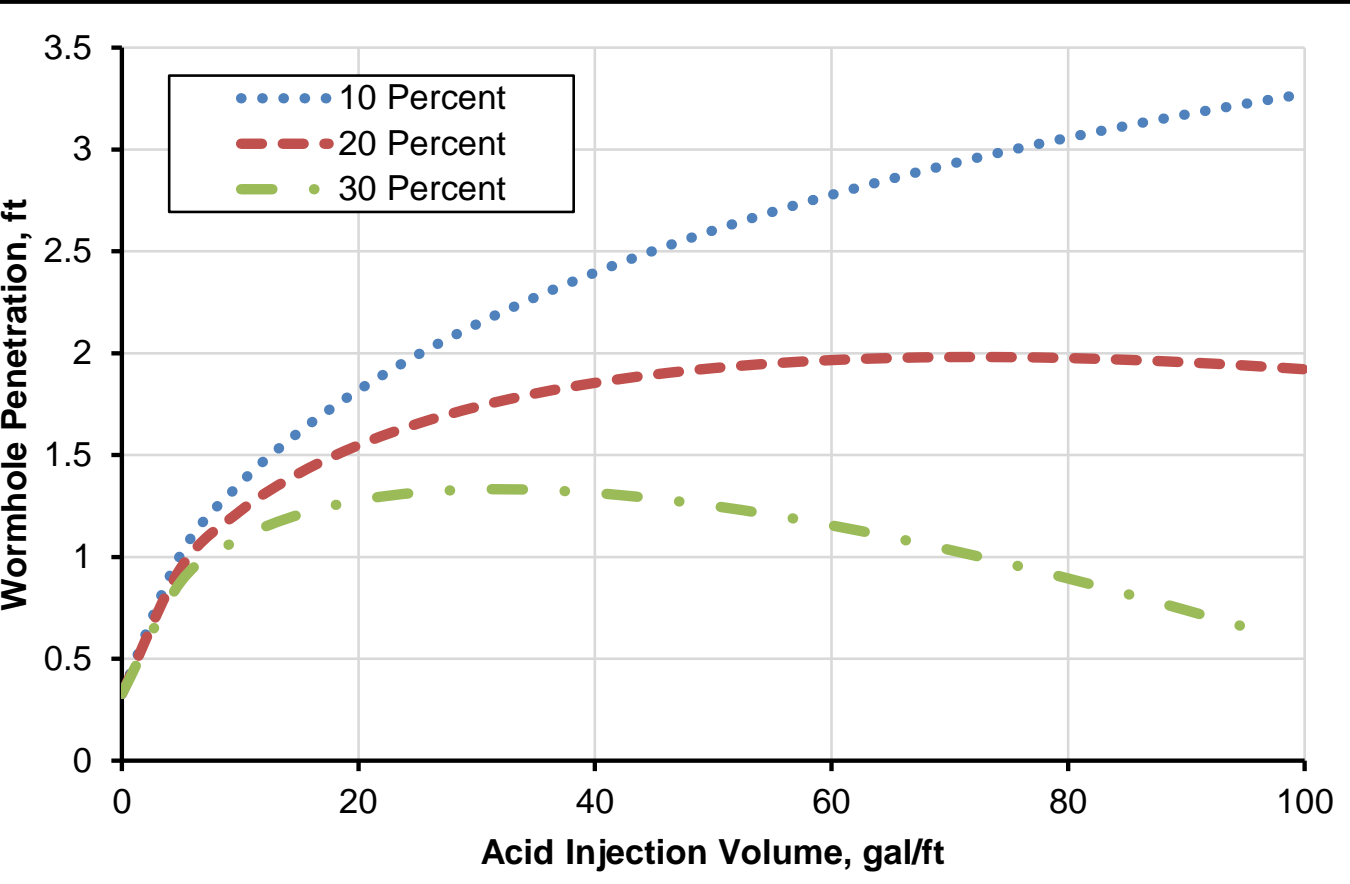

Fig. 10 Effect of acid concentration on wormholing with $30 \%$ formation porosity and $5.3 \mathrm{wt} . \%$ asphaltene

637 
Journal of Energy Resources Technology JUNE 2022, Vol. 144 / 063001-1

638

639

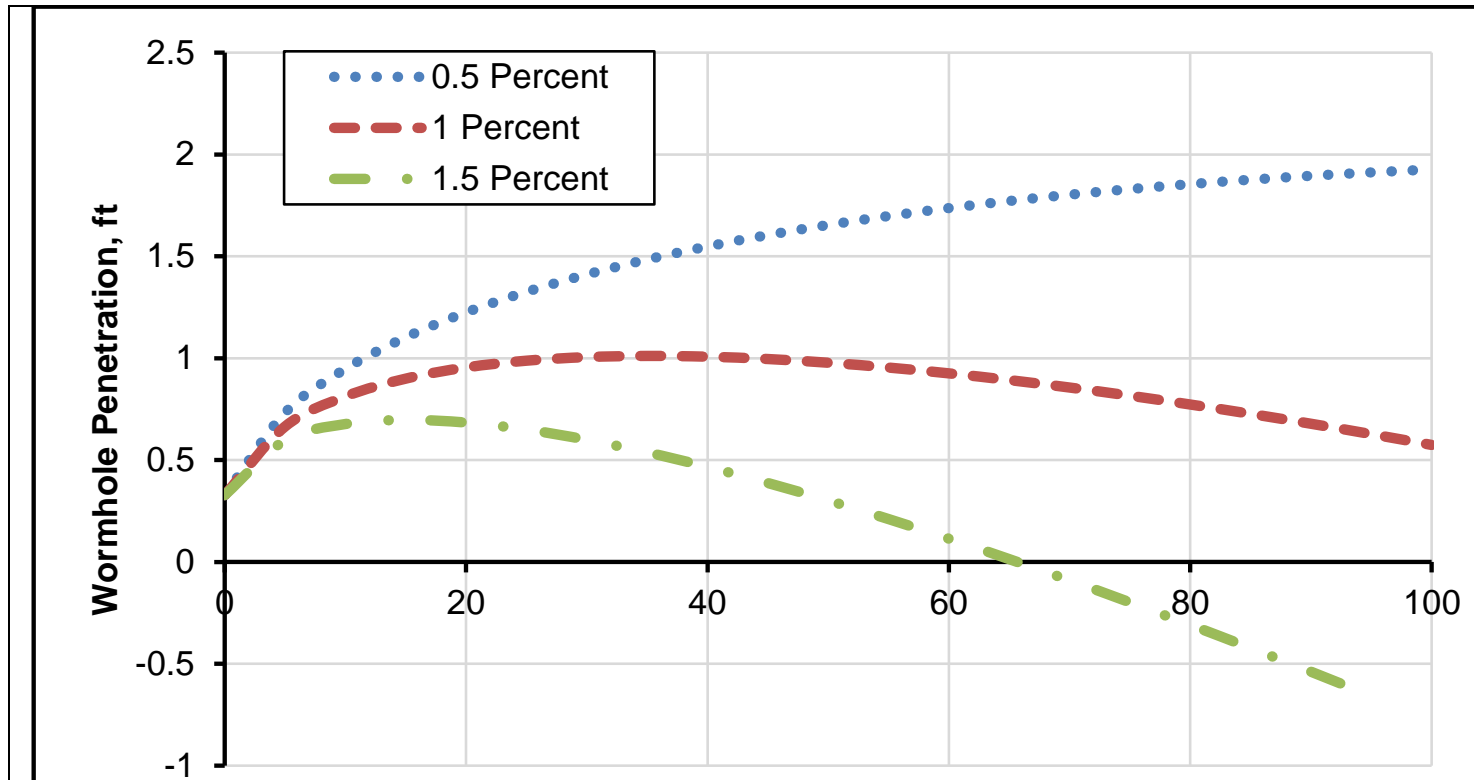

Acid Injection Volume, gal/ft

Fig. 11 Effect of asphaltene concentration on wormholing with $30 \%$ formation porosity and $15 \mathrm{wt} . \%$ acid concentration

640 
Journal of Energy Resources Technology JUNE 2022, Vol. 144 / 063001-1

641

642

Table 1 Summary of the input parameters used in the Acid-Asphaltene formation reaction

\begin{tabular}{|c|c|}
\hline Parameter & Value \\
\hline Formation Porosity $(\phi)$, percent & 30 \\
\hline Wellbore Radius $(r), \mathrm{cm}$ & 9.998 \\
\hline Acid Density $(\rho), \mathrm{g} / \mathrm{cm}^{3}$ & 1.07 \\
\hline Acid Concentration $\left(\mathrm{C}_{\mathrm{a}}\right), \%$ weight & 15 \\
\hline Acid Capacity Number $\left(N_{c}\right)$ & 0.035 \\
\hline Rock Density $(\rho), \mathrm{g} / \mathrm{cm}^{3}$ & 2.71 \\
\hline Rock Wormholing Efficiency $(\tau)$ & 0.0711 \\
\hline Reservoir Thickness $(h), \mathrm{m}$ & 30.49 \\
\hline Asphaltene Concentration $\left(C_{a s}\right), \%$ weight & 5.3 \\
\hline Asphaltene Reaction Rate Coefficient $(\chi)$ & $4.65 \times 10^{-3}$ \\
\hline Asphaltene Entrainment Rate Coefficient $(\beta)$ & 0.6 \\
\hline
\end{tabular}

643

644 